ORIGINAL ARTICLE

\title{
Efficacy of Graded Activity with and without Daily-Monitored- Walking on Pain and Back Endurance among Patients with Concomitant Low-Back Pain and Type-2 Diabetes: A Randomized Trial
}

\author{
Opeyemi Ayodiipo IDOWU ${ }^{1 *}$, Ade Fatai Adeniyi ${ }^{2}$
}

\section{OPEN ACCESS}

Citation: Opeyemi Ayodiipo IDOWU, Ade Fatai Adeniyi. Efficacy of Graded Activity with and without DailyMonitored Walking on Pain and Back Endurance among Patients with Concomitant Low-Back Pain and Type-2 Diabetes: A Randomized Trial. Ethiop J Health Sci.2020;30(2):233. doi:http://dx. doi.org/10.4314/ejhs.v30 i2.11

Received: August 18, 2019

Accepted: October 31, 2019

Published: March 1, 2020

Copyright: (C2020 Idowu O.A., et al. This is an open access article distributed under the terms of the Creative Commons Attribution License, which permits unrestricted use, distribution, and reproduction in any medium, provided the original author and source are credited. Funding: Nil Competing Interests: The authors declare that this manuscript was approved by all authors in its form and that no competing interest exists.

Affiliation and Correspondence:

${ }^{1}$ Department of Physiotherapy, School of Basic Medical Sciences, College of Medical Sciences, University of Benin, Benin-City, Nigeria

${ }^{2}$ Department of Physiotherapy, College of Medicine, College of Medicine, University of Ibadan, Nigeria

*Email: opeyemi.idowu@uniben.edu

\section{ABSTRACT}

BACKGROUND: There is evidence supporting the efficacy of Graded Activity (GA) in managing clinical attributes of patients with Low-Back Pain (LBP) in the general population. However, it is unknown whether $G A$ alone is efficacious in managing these clinical attributes in patients with concomitant LBP and Type-2 Diabetes (T2D) or additional daily-monitored walking will be required.

METHODS: A single-blind controlled trial involving 58 patients (mean age: $48.3 \pm 9.4$ years, $64.7 \%$ females) with concomitant $L B P$ and T2D who received treatment twice weekly for twelve weeks was conducted. Participants were randomized into $G A$ or $G A$ with daily-monitored-walking (GAMW) groups. Pain Intensity (PI), Static Back Extensors Endurance (SBEE), Static Abdominal Muscular Endurance (SAME) and Glycaemic Control (GC) were assessed using Visual Analogue Scale, Biering-Sorensen test, flexor endurance test, and in2itTM device respectively at baseline, 4th, 8th and 12th week. Data were analysed using repeatedmeasures ANOVA and Unpaired t-tests at $\alpha=0.05$.

RESULTS: There were significant differences in PI, SAME and $S B E E$ among participants in each of $G A$ and $G A M W$ groups respectively $(p<0.05)$. Within-group difference on $G C$ was significant for $G A M W(6.3 \pm 0.9 \%, 5.7 \pm 0.7 \%)$ but not $G A$ $(6.3 \pm 0.9 \%, 6.3 \pm 0.9 \%)$. There was significant difference $(p<0.05)$ between $G A$ and $G A M W$ group participants for $S B E E(7.2 \pm 0.1 \mathrm{sec}$, $7.3 \pm 0.1 \mathrm{sec})$ at week 8 of the study and $G C(-0.5 \pm 0.2 \%,-0.6 \pm 0.5 \%)$ at the end of the study. No differences were found between $G A$ and $G A M W$ groups for PI and SAME.

CONCLUSION: Graded activity with daily-monitored-walking produced positive effects on GC and yielded a better improvement on SAME and SBEE.

KEYWORDS: Graded activity, daily monitored walking, low back pain, type 2 diabetes mellitus. 


\section{INTRODUCTION}

Low back pain (LBP), a serious public health menace, is a leading cause of work-related disability and undue economic burden (1). The consequences of LBP include physical problems such as reduced back muscle strength and endurance (2). The lifetime prevalence estimates of LBP range from 49 to $70 \%$ (3). This implies that most people will experience LBP during their lives. Spontaneous recovery from LBP occurs within 3 months of onset in about $33.3 \%$ individuals (4). However, over $65 \%$ of these individuals will have LBP one year after (4).

Clinical guidelines support the use of exercises that encourage people with chronic LBP to assume a physically active role in their recovery (5). This may be attributed to the many health benefits of physical activity (PA) (6). However, LBP patients often report low levels of PA believing that pain felt because of movement may indicate re-injury (7). An example of an exercisebased treatment approach that encourages patients to be as physically active as possible despite pain is the graded activity (GA) (8). Graded activity comprises four parts: measurements of functional capacity, a work-place visit, back school education and an individual, submaximal, gradually increased exercise program (9). Further, GA utilizes basic psychological constructs of specific behavioural quotas and methodical reinforcement to progress a patient's therapeutic exercise and activity (8). Studies have shown GA to be a promising intervention for chronic LBP $(10,11)$. However, these favourable reports of GA found in the general population cannot be over-emphasized when considering LBP among individuals with Type 2 Diabetes mellitus (T2DM).

Although the exact aetiology of heightened LBP among patients with T2DM is unclear, there is evidence that a cascade of events cause a build-up of glycation-derived cross links within the collagenous rich tissues in the body. These events include glycosylation of proteins, atherosclerosis within the blood vessels, damage to vascular structures; and accumulation of collagen in the skin and periarticular structures (12). These glycationderived cross links may impact negatively on the normal function of the collagenous tissues in the body especially at the low back and consequently translate into patients experiencing diabetesinfluenced and/or mediated LBP (13). From the foregoing discussion, there is a need to find out whether GA is efficacious in the management of LBP in patients with underlying T2DM. Further, it is important to determine the efficacy of GA with an additional intervention (e.g. daily-monitoredwalking targeted at problems of T2DM that perpetuate LBP including hyperglycaemia and muscle weakness). This study, therefore, aimed to investigate the efficacy of GA with and without daily-monitored-walking on pain intensity, static back flexors and static back extensors muscle endurance among patients with concomitant LBP and T2DM.

\section{MATERIALS AND METHODS}

Design: This study was a single-blind randomized clinical trial with repeat measures at baseline and at the end of weeks 4,8 and 12 of intervention. The University of Ibadan/University College Hospital Health Research and Ethics Committee (UI/EC/13/0093) gave ethical approval for this study.

Participants: A total number of 58 patients with concomitant chronic non-specific LBP and T2DM were recruited from the Medical Outpatient and Physiotherapy Departments of the Federal Medical Center, Ido-Ekiti, Nigeria, and the University of Benin Teaching Hospital, Benin-City, Nigeria. Prior to the commencement of baseline testing, participants read the study information sheet, asked questions about their participation, and following a verbal explanation of the study procedures, read and signed a consent form. Participants then completed general questions regarding personal details as well as durations of diagnosis of LBP and T2DM. Participants were deemed eligible to take part in the study if they had chronic non-specific LBP of not less than 3 months with concomitant T2DM and understood either English or Yoruba language. Participants were excluded from the study if they had morbidities beside T2DM (like uncontrolled hypertension, stroke, and asthma), unstable glycaemic control, additional disabling conditions such as severe peripheral neuropathy and amputations, red flags suggestive of severe spinal pathology or inability to understand the

DOI: http://dx.doi.org/10.4314/ejhs.v30i2.11 
instructions or complete the study assessments. Two physiotherapists who were recruited as research assistants coordinated recruitment, eligibility screening, and assignment of the patients into the treatment groups. The research assistants were blinded to the interventions received by each group. Participants were randomized into one of two groups: Graded Activity Group (GAG) and Graded Activity with-daily-monitored-walking (GAMW) Group.

Interventions: Both groups received GA, while participants in the GAMW Group (GAMWG) received an additional pedometer-driven dailymonitored-walking as PA intervention. Only the first author carried out the interventions. The GA intervention followed the program described by Lindstrom et al. $(8,9)$ based on individual sessions of progressive and sub-maximal exercises aimed at improving physical fitness and stimulate changes in behaviour and patients' attitudes to pain. The 1hour GA program comprised aerobic exercises on an elliptical cycle, abdominal sit-up exercises, dynamic back extension exercises, bent over row dumbbell exercises, and squatting exercises. The researcher reviewed exercise targets for each participant at the end of each week by determining the maximum functional capacity of each patient. The patient performed the abdominal situp, dynamic back extension, and squatting exercises to near fatigue. The researcher then noted the number of times the participant could perform the exercise. Thereafter, $60 \%$ of this number was documented as the exercise quota for the week. New exercise quotas for the participants were determined weekly through the same procedure. The 1-repetitive maximum (RM) test was used to determine the load of strengthening exercises. During the first week of training, individuals exercised using $60 \%$ of their maximum load. New 1-RM was determined weekly for participants. The target heart rate of each participant was calculated using the Karvonen's formula.

In addition, patients were individually taught the main content of the Nigerian Back School which contained important information on the basic anatomy, functions of the muscles, functions of the back, and LBP disability treatments (15). The researcher also visited the workplace and home of each patient at baseline, weeks 4 and 8 of the GA interventions. The purposes of the work-place and home visits were to give the patient an opportunity to show his/her work and home situation, to enable the participant's employment manager (if any) to become actively involved in the rehabilitation process. Participants in GAMWG had an objectively daily-monitored-walking programme besides GA. Participants were instructed to achieve the daily recommended level beneficial for health and wellbeing. This was based on the 5,500 daily steps recommendation for patients with chronic illness (16). Pedometer step counts were collected and used as an index to monitor adherence to the walking programme.

Outcome measures: Primary outcome measures included Pain Intensity (PI) using a VAS, Static Back Extensor Muscles' Endurance (SBEE), and Static Abdominal Muscular Endurance (SAME). A secondary measure of Glycaemic Control (GC) was assessed. The SBEE was assessed using the Biering-Sorensen test of static muscular endurance. It measured how long (to a maximum of 240 seconds) a participant could maintain the unsupported trunk (from the anterior iliac crests level up) horizontally while lying prone on a test bench (17). The flexor endurance test was used to assess the SAME of participants. Two strips of tape were placed parallel to each other and 3.5 inches (8.9 centimetres) apart. The participant lay supine on the mat with knees at right angles; the participant extended the arm so that the fingertips of both hands touched a strip of tape perpendicular to the body on both sides. The participant was asked to slide the fingertips on the mat until it reached the second set of tape strips. Then participant was to maintain this position for as long he or she could without moving their fingertips away from the second tape strip. The period of hold was noted with a stopwatch (17). A point-of-care system (In2it, Biorad Latvia) was used to assess participants' HBA1c. Using Cohen's table at 0.05 $\alpha$ - level, $80 \%$ power and an effect size of 0.8 (large), a group sample $(n)=20$ was adopted for the study. The sample size $(\mathrm{N})$ for the study was a minimum of 40 participants. 
Data analysis: The data analyses were carried out using SPSS Statistics version 20.0 software (IBM Corp., Armonk, New York, USA). Descriptive statistical methods were used to describe the samples. Repeated measures analysis of variance (ANOVA) was used to determine within-group differences on PI, SAME and SBEE. Paired ttest was used to compare the glycaemic control from baseline to week 12 for each GAG and GAMWG. Independent samples t-test was used to compare the mean change of primary outcomes and glycaemic control between the two groups. Effect sizes were calculated for the mean change of primary outcomes. For all analyses, level of significance was set at $\mathrm{p}<0.05$.

\section{RESULTS}

Flow of participants: Fifty-eight consecutive patients $(48.3 \pm 9.4$ years, $65 \%$ females $)$ with concomitant Low Back Pain (LBP) and Type 2 Diabetes mellitus (T2DM) who met the inclusion criteria and agreed to participate in the study were randomized (29 per group) into GAG and GAMWG. The flow chart of recruitment is presented in Figure 1.

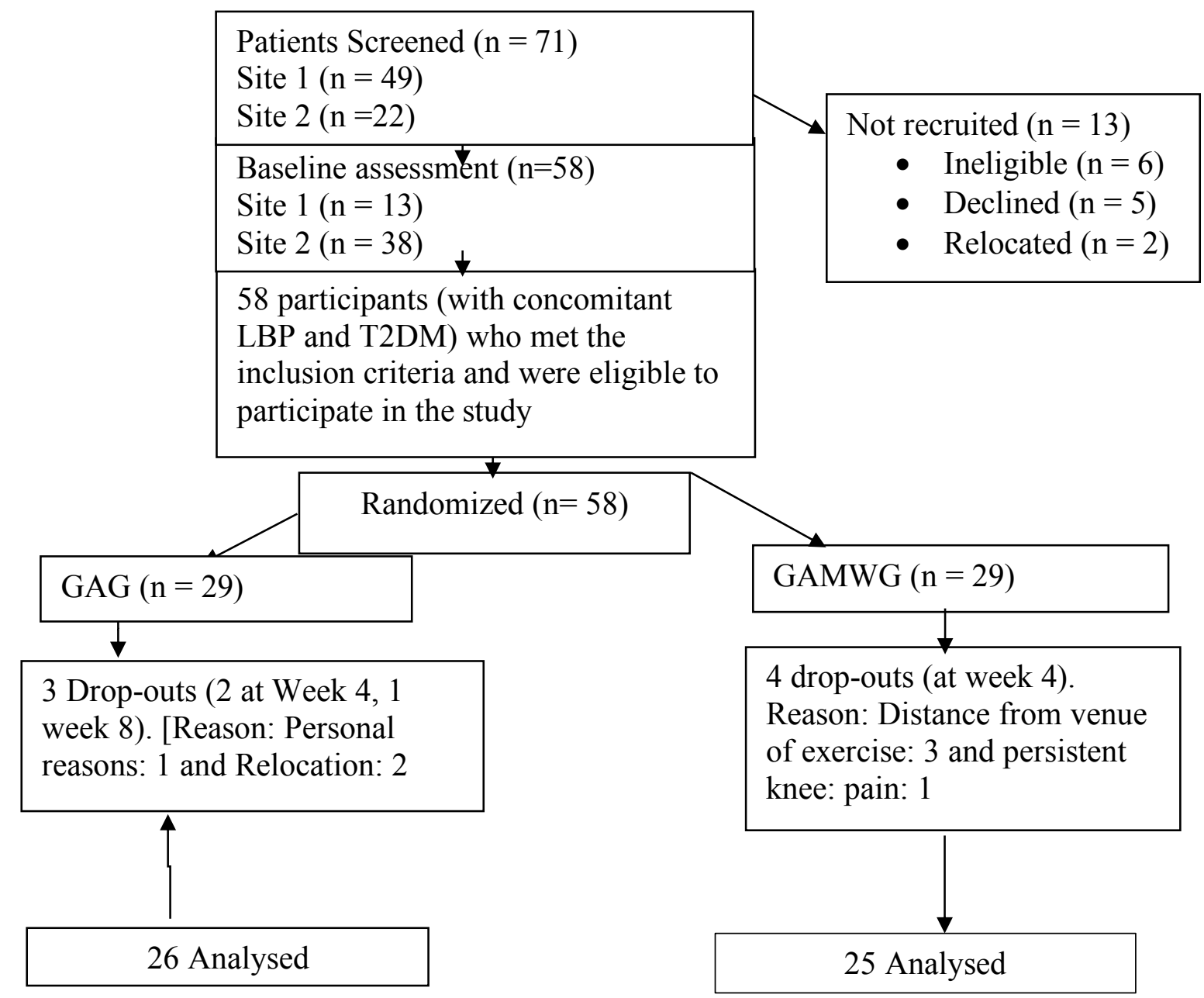

Figure 1: Flowchart of participants' recruitment and participation

Socio-demographic and baseline characteristics of participants: The mean age, weight, height, BMI, duration of diagnosis of LBP and duration of the diagnosis of T2DM of all the participants were
$48.3 \pm 9.4$ years, $68.8 \pm 5.8 \mathrm{Kg}, 1.60 \pm 0.05$ metres, $26.9 \pm 4.0 \mathrm{Kg} / \mathrm{m} 2,17.3 \pm 18.6$ months and $33.8 \pm 16.8$ months, respectively. The two groups were comparable in their baseline characteristics. The 
socio-demographic and baseline characteristics of

2. the participants are presented in Table 1 and Table

Table 1: Socio-demographic characteristics of all participants by treatment.

\begin{tabular}{llll}
\hline Variable & GAG $(\mathbf{n = 2 6})$ & GAMWG (n=25) & Total $(\mathbf{n}=\mathbf{5 1})$ \\
\hline Gender & & & \\
Male & $10(38 \%)$ & $8.0(32 \%)$ & $18(35 \%)$ \\
Female & $16(62 \%)$ & $17(68 \%)$ & $33(65 \%)$ \\
Marital status & & & \\
Married & $25(96 \%)$ & $24(96 \%)$ & $49(96 \%)$ \\
Widowed & $1(4 \%)$ & $1.0(4 \%)$ & $2(4 \%)$ \\
Education & & & \\
Pry School & $0(0 \%)$ & $6(24 \%)$ & $6.0(12 \%)$ \\
Sec. School & $6.0(23 \%)$ & $6(24 \%)$ & $12(23 \%)$ \\
Poly. & $2.0(8 \%)$ & $2(8 \%)$ & $4.0(8 \%)$ \\
University & $18(69 \%)$ & $11(44 \%)$ & $29(57 \%)$ \\
Occupational Status & & & \\
Unemployed & $4(15 \%)$ & $3(12 \%)$ & $7.0(15 \%)$ \\
Employed & $18(70 \%)$ & $17(68 \%)$ & $35(68 \%)$ \\
Retiree & $4(15 \%)$ & $5(20 \%)$ & $9.0(17 \%)$ \\
\hline
\end{tabular}

GAG - Graded Activity Group, GAMWG - Graded Activity with daily Monitored Walking Group, Pry - Primary Sec - Secondary, Poly - Polytechnic

Table 2: Comparison of the participants' baseline general characteristic by treatment groups

\begin{tabular}{lllll}
\hline Variable & GAG (n=26) & GAMWG (n=25) & \\
\hline & Mean (SD) & Mean (SD) & t-value & p-value \\
Age (years) & $48.27(9.56)$ & $48.28(9.41)$ & -0.00 & 0.99 \\
BMI $\left(\mathrm{Kg} / \mathrm{m}^{2}\right)$ & $27.32(2.22)$ & $26.48(3.62)$ & 1.00 & 0.31 \\
Pain Intensity (cm) & $6.95(0.10)$ & $6.95(0.08)$ & 0.22 & 0.83 \\
SAME (sec) & $22.41(0.39)$ & $22.48(0.27)$ & -0.68 & 0.50 \\
SBEE (sec) & $22.98(0.25)$ & $23.02(0.24)$ & -0.52 & 0.61 \\
Gly. Ctr. (\%) & $6.31(0.87)$ & $6.33(0.90)$ & 0.10 & 0.92 \\
\hline
\end{tabular}

GAG- Graded Activity Group, GAMWG - Graded Activity with daily Monitored Walking Group, SD - Standard Deviation, BMI - Body Mass Index, SAME - Static Abdominal Musculature Endurance, SBEE - Static Back Extensors Endurance, Gly. Ctr - Glycaemic Control

Effects of intervention: There were differences in PI, SAME and SBEE across the four-time points of the study for participants in each of GAG and GAMWG (Table 3). Within-group analysis of glycaemic control was significant for GAMWG $(6.3 \pm 0.9 \%, \quad 5.7 \pm 0.6 \%$; Effect size $(\mathrm{ES})=1.16(95 \% \mathrm{CI}=0.65$ to 1.67$), \mathrm{p}=0.00)$ but not GAG $(6.3 \pm 0.8 \%, 6.3 \pm 0.9 \%$; ES $=0.21,95 \%$
$\mathrm{CI}=-0.3$ to 0.72 ), $\mathrm{p}=0.29$ ) participants. Table 4 shows the weeks 4,8 , and 12 comparisons of participants' clinical outcome variable mean changes between participants in the GAG and GAMWG. Participants in the GAMWG had significantly higher mean change on SBEE scores than GAG scores at week 8 of the study. There was also a statistically significant difference in 
the mean change glycaemic control between GAG and GAMWG participants $(-0.05 \pm 0.2 \%$, $\mathrm{p}=0.00)$ over the baseline through week 12 of the $0.6 \pm 0.5 \%) ; \quad \mathrm{ES}=1.58 ; 95 \% \quad \mathrm{CI}=1.07$ to 2.09 , study.

Table 3: Repeated measures ANOVA of participants' clinical outcome variables of PI, SAME and SBEE in the GAG and GAMWG across the 4-time points of the study

\begin{tabular}{llll}
\hline Variable & Time Frame & GAG $(\mathbf{n}=\mathbf{2 6})$ & GAMWG (n=25) \\
\hline PI $(\mathrm{cm})$ & & Mean (SD) & Mean (SD) \\
& Week 0 & $6.95(0.10)^{\mathrm{a}}$ & $6.95(0.08)^{\mathrm{a}}$ \\
& Week 4 & $6.15(0.09)^{\mathrm{b}}$ & $6.11(0.09)^{\mathrm{b}}$ \\
& Week 8 & $4.43(0.07)^{\mathrm{c}}$ & $4.40(0.07)^{\mathrm{c}}$ \\
F-value & Week 12 & $2.95(0.09)^{\mathrm{d}}$ & $2.87(0.14)^{\mathrm{d}}$ \\
p-value & & 20513.03 & 14360.79 \\
SAME (sec) & & $<0.001^{*}$ \\
& Week 0 & $22.41(0.39)^{\mathrm{a}}$ & $22.48(0.27)^{\mathrm{a}}$ \\
& Week 4 & $29.05(0.34)^{\mathrm{b}}$ & $29.13(0.20)^{\mathrm{b}}$ \\
F-value & Week 8 & $36.06(0.20)^{\mathrm{c}}$ & $36.16(0.11)^{\mathrm{c}}$ \\
p-value & Week 12 & $41.22(0.17)^{\mathrm{d}}$ & $41.35(0.08)^{\mathrm{d}}$ \\
SBEE (sec) & & 106331.45 & 157679.94 \\
& & $<0.001^{*}$ & $<0.001^{*}$ \\
Week 0 & Week 4 & $22.98(0.25)^{\mathrm{a}}$ & $23.02(0.24)^{\mathrm{a}}$ \\
p-value & Week 8 & $25.35(0.21)^{\mathrm{b}}$ & $25.37(0.21)^{\mathrm{b}}$ \\
& Week 12 & $32.61(0.19)^{\mathrm{c}}$ & $32.71(0.14)^{\mathrm{c}}$ \\
& & $37.11(0.14)^{\mathrm{d}}$ & $37.24(0.13)^{\mathrm{d}}$
\end{tabular}

Table 4: Comparison of (mean change of) clinical outcome variables (PI, SAME and SBEE) between participants in GAG and GAMWG at weeks 4, 8 and 12 of the study

\begin{tabular}{ll|lll|l}
\hline Variable & Time Frame & GAG $(\mathbf{n}=26)$ & GAMWG $(\mathbf{n}=25)$ & Effect size $(95 \%$ CI) & p-value \\
\hline \multirow{2}{*}{ PI (cm) } & Week 4 & Mean (SD) & Mean (SD) & & \\
& Week 8 & $-0.81(0.03)$ & $-0.83(0.06)$ & $0.5(0.42$ to 0.58) & 0.08 \\
& Week 12 & $-1.71(0.06)$ & $-1.71(0.09)$ & $0.04(-0.04,0.12)$ & 0.99 \\
SAME (sec) & Week 4 & $-1.48(0.09)$ & $-1.53(0.12)$ & $0.47(0.39$ to 0.55$)$ & 0.09 \\
& Week 8 & $7.0(0.16)$ & $7.0(0.10)$ & $-0.06(-0.14$ to 0.02) & 0.83 \\
& Week 12 & $5.2(0.05)$ & $5.2(0.0)$ & $-0.95(-1.02$ to 0.87$)$ & 0.58 \\
SBEE (sec) & Week 4 & $2.4(0.08)$ & $2.4(0.10)$ & $90.45(-0.53$ to -0.37$)$ & 0.12 \\
& Week 8 & $7.2(0.10)$ & $7.3(0.10)$ & $0.12(0.04$ to 0.2$)$ & 0.67 \\
& Week 12 & $4.5(0.06)$ & $4.5(0.08)$ & $-0.95(-1.02$ to -0.87$)$ & $0.00 *$ \\
\hline
\end{tabular}

GAG - Graded Activity Group, GAMWG - Graded Activity Protocol with daily Monitored Walking Group, SD - Standard Deviation, SAME - Static Abdominal Musculature Endurance, SBEE - Static Back Extensors Endurance, *Indicates significance at $\alpha=0.05$ 


\section{DISCUSSION}

Results from this study showed that graded activity (GA) reduced pain intensity among patients with concomitant low back pain (LBP) and Type 2 Diabetes Mellitus (T2DM). Further GA significantly increased the static abdominal muscular endurance (SAME) and static back extensors endurance (SBEE) of participants across the time points of the study. The graded activity with daily monitored walking (GAMW) intervention had significant improvements in pain intensity (PI), SAME and SBEE of patients with concomitant LBP and T2DM. Compared to GA alone, GAMW led to more significant improvements on SBEE at week 8 and improved glycaemic control at the end of week 12 .

The reduction in pain intensity of patients with concomitant LBP and T2DM following GA in this study follows the same trend as reported by other studies from the general population $(8,10$ 11,18,20). For instance, Bello and colleagues found improvements in the PI of patients with chronic non-specific LBP after going through GA (11). However, in contrast to the present study, Steenstra et al. (21) reported that GA did not improve the back pain of workers. A major difference between the present study and that of Steenstra et al. was the extent to which the interventions were standardized. In this study, only I.O.A administered GA to the participants, and to a large extent could standardize the intervention. Steenstra and colleagues (21) referred patients to 16 facilities with about 47 physiotherapists and attempted to standardize their intervention. However, uniformity in interventions was unreachable (21). We attribute the positive effect of GA on the SAME and SBEE of patients with concomitant LBP and T2DM in this study to the effect of the treatment component of the GA.

Our results are similar to those of previous studies which reported that GA increased the back muscle endurance of patients with $\operatorname{LBP}(19,20)$. Lindstrom et al., however, reported a significant increase in the SAME but not SBEE of patients with LBP following GA (9). Our study and that of Roche and colleagues (19) reported only the short-term effect of GA on SBEE and SAME,
Kankaanpa et al. (20) and Lindstrom et al. (9) however, had conflicting reports on the longterm effects of GA on SBEE and SAME. While Kankaanpa et al (20) surmised that the increase in the SBEE and SAME following GA diminished on the long term, Lindstrom and colleagues reported that GA improved both SAME and SBEE significantly at 1-year follow-up. A major difference between the study of Lindstrom et al. and other studies, including this study, was the class of LBP being treated. Lindstrom et al. concentrated on patients with sub-acute LBP, others focussed on patients with chronic LBP. In addition, the present study further differs from previous studies because participants comprised patients with concomitant LBP and T2DM.

Strengthening exercises aimed at the abdominal and back extensor muscles is premised on the known relationship between the weaknesses of these two muscle groups and LBP (22). Chronic LBP results in physical impairments, such as poor trunk and extremity muscle endurance, and alteration of muscle activation patterns (20). This results in lumbar instability and an increased risk of lumbar spine re-injury. Graded activity relieves back symptoms via the development of a sense of control over pain, elimination of pain avoidance, and improving overall physical fitness/function (11). When patients complete their exercises and discover that such exercises were not harmful to their back as they might have previously thought, they are likely to gain trust in the function of their back.

Thus, they adjust their maladaptive pain beliefs, which ultimately lead to an improvement in physical functioning (11). Other suggested mechanisms through which exercises impact positively on LBP clinical outcomes include: modification of motor control patterns because of the weighting of sensory inputs, and possibly from a positive therapist-patient interaction or relationship (24). Thus, GA not only tackles pain and disability via the modification of mal-adaptive LBP behaviours but also corrects impairments such as reduced muscle strength and reduced endurance.

Asides the fact that the components of the GA may have led to reduced pain and increased muscular endurance, additional daily-monitored-

DOI: http://dx.doi.org/10.4314/ejhs.v30i2.11 
walking intervention may have further encouraged movement and an increase in PA despite the pain. This increase in the PA of the patients that received GAMW may have provided additional opportunities for healing in participants' musculoskeletal systems. Physical activity facilitates healing in the musculoskeletal system by increasing peripheral circulation and nutrient supply to the back extensor musculature, mobilizing stiff joints, mechanically affecting disc pathology or a combination of all these different effects (25). As the primary aim of the GA is to get patients with LBP to be more physically active and be able to confront their fears about PA, daily monitored walking may provide additional PA opportunities.

Compared to GA alone, GAMW led to a higher, more significant improvement on SBEE at week 8 and improved glycaemic control at the end of week 12. This result addresses the important research question whether the aerobic exercise in the treatment component of the GA is enough to manage patients with concomitant LBP and T2DM. It is adducible from the result that patients with concomitant LBP and T2DM will require an additional daily-monitored-walking home programmes which may not only address their LBP concerns but also improve their glycaemic control. Graded activity with monitored walking had significant positive effects on the glycaemic control of patients with concomitant LBP and T2DM than those who had GA alone. This might have led to improved general health status, increased exercise tolerance and increased PA. This may have resulted in reduced maladaptive and incongruent back pain behaviour, thus improving LBP outcomes among the participants who had GAMW.

Alongside medication and diet, PA is important in attaining glucose control in patients with T2DM (25). There is accruing evidence that walking, a form of PA has beneficial effects on glycaemic control (26) and LBP (27). Walking is a moderate-intensity exercise with less risk of developing adverse cardiovascular or musculoskeletal injuries compared to more vigorous forms of exercise (28). Further, directly monitoring the PA of patients with LBP could serve as an adjunct to the main treatment regimen (29). Home-based walking programmes can be monitored through accelerometers and also by the use of pedometers. Pedometers are a better choice for the feedback of accumulated PA in clinical and real-life situations because it is relatively cheap and simple to understand (30). The pedometer can both serve as a feedback mechanism for PA activity (steps/day) accumulated by an individual and provide a benchmark for attainable PA. To enjoy the health benefits of walking as a form of PA, experts recommend 10,000 steps per day for the general population (16). Attaining this PA recommendation may however be impractical for T2DM, as these patients have to deal with myriad diabetic complications, including hyperglycaemia. Tudor-Locke and colleagues suggested that in individuals with chronic illnesses such as T2DM, it is more appropriate to work with gradual increases, based on the baseline number of steps (16).

To the best of our knowledge, this is the first LBP intervention study conducted in a well-defined T2DM population. Further, this study is one of the very limited studies that assessed the effects of GA on back muscle endurance.

This study is, however, not without limitations. It only assessed the short-term effect of GA; therefore, the results should be interpreted with caution. Second, the oral antidiabetic agents taken by some participants were not controlled for in this study. This, besides diet, could have in one way or the other influenced such individuals' responses to exercise. Patients with chronic pain (LBP) often experience impairments in attention control, working memory, mental flexibility, problem-solving, and information processing speed. Further, pain experience may affect one's personal judgments concerning such an individual's ability to engage successfully in specific behaviours that lead to specific, desired outcomes. An exercise intervention such as the GA, which is quota-based and submaximal, may help to address these problems. Future studies should explore whether GA will be more effective between individuals with or without T2DM.

\section{ACKNOWLEDGEMENT}

The authors would like to thank all the patients who took part in this study. 


\section{REFERENCES}

1. Kasebaum NJ, Arora M, Barber RM, Bhutta ZA, Brown J, Carter A et al. Global, regional, and national disability-adjusted life-years (DALY) for 315 diseases and injuries and healthy life expectancy (HALE), 1990-2015. Lancet. 2016; 388: 1603-58.

2. Mbada CE, Ayanniyi O, Ogunlade SO. Relationship between pain intensity, activity limitation, static and dynamic back muscles endurance in patients with non-specific long term low-back pain. Journal of Nigeria Society of Physiotherapy. 2011; 18:14-21.

3. van Tulder MW, Koes BW, Bombardier C. Low back pain. Best Practice and Research in Clinical Rheumatology. 2002; 16:761-75. http://dx.doi.org/10.1053/berh.2002.0267

4. Airaksinen O, Brox JI, Cedraschi C, Hilderbrandt J, Klaber-Moffett J, Kovacs F, et al. European guidelines for the management of chronic nonspecific low back pain; Cost B13 Working Group on Guidelines for Chronic Low Back Pain. European Spine Journal. 2006; 15:S192-S300. http://dx.doi.org/10.1007/s00586-006-1072-1

5. Koes BW, van Tulder M, Lin CC, Macedo LG, McAuley J, Maher C. An updated over view of clinical guidelines for the management of non-specific low back pain in primary care. European Spine Journal. 2010; 19:2075-94.

http://dx.doi.org/10.1007/s00586-010-1502-y

6. Warburton DE, Nicol CW, Bredin SD. Health benefits of physical activity: the evidence. Canadian Medical Association Journal. 2006; 14:174.

http://dx.doi.org/10.1503/cmaj.051351

7. Pincus T, Burton A, Vogel S, Field A. A systematic review of psychological factors as predictors of chronicity/disability in prospective cohorts of low back pain. Spine. 2002; 27: E1109-E120. http://dx.doi.org/10.1097/00007632200203010-00017

8. Lindstrom I, Ohlund C, Eek C, Wallin L, Peterson L, Fordyce WE et al. The Effect of Graded Activity on Patients with Subacute
Low Back Pain: A Randomized Prospective Clinical Study with an Operant-Conditioning Behavioural Approach. Physical Therapy. 1992; 72:279-93.

9. Lindstrom I, Ohlund C, Eek C, Wallin L, Peterson L, Nachemson A. Mobility, strength, and fitness after a graded activity program for patients with subacute low back pain. A randomized prospective clinical study with a behavioural therapy approach. Spine. 1992; 17:641-52.

http://dx.doi.org/10.1097/00007632199206000-00003

10. Henschke N, Ostelo RW, van Tulder MW, Vlaeyen JW, Morley S, Assendelft WJ et al. Behavioural treatment for chronic low-back pain. Cochrane Database of Systematic Reviews. 2010 7; CD002014. doi: 10.1002/14651858.CD002014.pub3.

11. Bello AI, Quartey JNA, Lartey M. Efficacy of Behavioural Graded Activity Compared with Conventional Exercise Therapy in Chronic Nonspecific Low Back Pain: Implication for Direct Health Care Cost. Ghana Medical Journal. 2015; 49:173-80. http://dx.doi.org/10.4314/gmj.v49i3.8

12. Reddy G. Glucose-mediated in vitro glycation modulates biomechanical integrity of the soft tissues but not hard tissues. Journal of Orthopaedic Research. 2003; 21:738-43. http://dx.doi.org/10.1016/S07360266(03)00006-8

13. Eivazi M, Abadi L. Low Back Pain in Diabetes Mellitus and importance of preventive approach. Health Promotion Perspectives. 2012; 2: 80-8.

14. Whaley $\mathrm{MH}$, Brubaker $\mathrm{PH}$, Otto RM, Armstrong LE. ACSM's guidelines for exercise testing and prescription. $7^{\text {th }}$ ed. Philadelphia (PA): Lippincott Williams and Wilkins; 2006: 286-99.

15. Odebiyi DO. How to avoid back pain at work and rest: a handbook of the Nigerian Back School. Lagos. Crowntex Press; 2004: 1-17.

16. Tudor-Locke C, Craig CL, Aoyagi Y, Bell $\mathrm{RC}$, Croteau KA, De Bourdeaudhuij I, et al. How many steps/day are enough? For older adults and special populations. International

DOI: http://dx.doi.org/10.4314/ejhs.v30i2.11 
Journal of Behavioural Nutrition and Physical Activity. 2011; 8:80. http://dx.doi.org/10.1186/1479-5868-8-80

17. Mbada CE, Adeyemi OO, Johnson OE, Dada OO, Awofolu OO, Oghumu SN. Normative values of static and dynamic abdominal muscles' endurance in apparently healthy Nigerians. Medical Rehabilitation. 2010; 14:21-8.

18. Magalhães MO, Muzi LH, Comachio J, Burke TN, Renovato França FJ, Vidal Ramos LA et al. The short-term effects of graded activity versus physiotherapy in patients with chronic low back pain: a randomized controlled trial. Manual Therapy. 2015; doi: 10.1016/j.math.2015.02.004

19. Roche G, Ponthieux A, Parot-Shinkel E, Jousset N, Bontoux L, Dubus V, PenneauFontbonne D, Roquelaure Y, Legrand E, Colin D, Richard I, Fanello S. Comparison of a functional restoration program with active individual physical therapy for patients with chronic low back pain: a randomized controlled trial. Archives of Physical Medicine and Rehabilitation. 2007; 88:1229.

20. Kankaanpää M, Taimela S, Airaksinen O, Hänninen $\mathrm{O}$. The efficacy of active rehabilitation in chronic low back pain. Effect on pain intensity, self-experienced disability, and lumbar fatigability. Spine. 1999 24:1034.

21. Steenstra IA, Anema JR, Bongers PM, de Vet HC, Knol DL, van Mechelen W. The effectiveness of graded activity for low back pain in occupational healthcare. Occupational and Environmental Medicine. 2006; 63:718.

22. Javadian Y, Behtash H, Akbari M, TaghipourDarzi M, Zekavat $\mathrm{H}$. The effects of stabilizing exercises on pain and disability of patients with lumbar segmental instability. Journal of Back and Musculoskeletal Rehabilitation. 2012; 25:149-55.

23. Kankaanpaa, M., Taimela, S., Airaksinen, O.J., Hannien, O. The efficacy of active rehabilitation in chronic low back pain. Effects on pain intensity; self-experienced disability and lumbar fatigability. Spine. 1999; 24: 1034-42.
24. Wand BM, Parkitny L, O'Connell NE, Luomajoki H, McAuley JH, Thacker $\mathrm{M}$ et al. Cortical changes in chroniclow back pain: current state of the art and implications for clinical practice. Manual Therapy. 2011; 16:15-20.

25. Van Dyck D, De Greef K, Deforche B, Ruige J, Bouckaert J, Tudor-Locke CE, Kaufman JF, De Bourdeaudhuij I. The relationship between changes in steps/day and health outcomes after a pedometer-based physical activity intervention with telephone support in type 2 diabetes patients. Health Education Research. 2013; 28: 539-45.

26. Qiu S, Cai X, Schumann U, Velders M, Sun $Z$, Steinacker JM. Impact of walking on glycaemic control and other cardiovascular risk factors in type 2 diabetes: a metaanalysis. PLoS One 2014; 9:e109767.

27. Cyarto EV, Myers A, Tudor-Locke C. Pedometer accuracy in nursing home and community dwelling older adults. Medicine and Science in Sports and Exercise. 2004; 36: 205-9.

28. Sitthipornvorakul E, Klinsophon T, Sihawong $\mathrm{R}$, Janwantanakul P. The effect of walking intervention in patients with chronic low back pain: a Meta-analysis of randomized controlled trials. Musculoskeletal Science and Practice. 2018; 34:38-46.

29. Jolly K, Taylor RS, Lip GY, Stevens A. Home-based cardiac rehabilitation compared with centre-based rehabilitation and usual care; A systematic review and meta-analysis. International Journal of Cardiology. 2006; 111:343-51.

30. Lin CC, McAuley JH, Macedo L, Barnett DC, Smeets RJ, Verbunt JA. Relationship between physical activity and disability in low back pain: A systematic review and meta-analysis. Pain. 2011; 152: 607-13. http://dx.doi.org/10.1016/j.pain.2010.11.034

31. Cyarto EV, Myers A, Tudor-Locke C. Pedometer accuracy in nursing home and community dwelling older adults. Medicine and Science in Sports and Exercise. 2004; 36: 205-9. 